\title{
Ulectomia uma alternativa cirúrgica no retardo da erupção dentária: relato de caso
}

Ulectomy a surgical alternative to delayed tooth eruption: case report

Ulectomía una alternativa quirúrgica en el retardo de la erupción dentaria: relato de caso

Cléia Maria de SOUZA ${ }^{1}$

Leidiane Rezende MARTINS ${ }^{1}$

Carla Oliveira FAVRETTO ${ }^{2}$

${ }^{1}$ Curso de Graduação em Odontologia, Faculdade de Odontologia de Mineiros, FAMP-Faculdade Morgana Potrich, 75830-000 Mineiros-GO, Brasil ${ }^{2}$ Doutora em Ciência Odontológica - Saúde Bucal da Criança Faculdade de Odontologia de Araçatuba-SP, UNESP, Professora de Odontopediatria, FAMP- Faculdade Morgana Potrich, 75830-000 Mineiros-GO, Brasil

\section{Resumo}

O processo de cronologia da erupção dentária é uma parte integrante do crescimento e desenvolvimento infantil. No entanto, o atraso na erupção dos dentes é algo frequente em muitas crianças, sendo necessário o cirurgião-dentista e/ou odontopediatra saber avaliar cada caso. Um dos motivos relacionados a esse atraso é a fibrose gengival, que após uma avaliação clínica e exame radiográfico minuciosos da região, constatando-se ausência de tecido ósseo, opta-se pelo tratamento por meio da técnica de ulectomia, a qual consiste na exérese dos tecidos que revestem a face incisal da coroa dentária de um dente não irrompido, com o objetivo de permitir um caminho livre para esse dente vir a ocupar sua posição na arcada. O objetivo desse trabalho é relatar um caso clínico de não irrupimento dos dentes 11 e 21 . A paciente compareceu na policlínica da FAMP com a queixa de ausência dos dentes da frente, que após o exame clínico e radiográfico, observou-se que tratava de um retardo de erupção devido a um fibrosamento gengival e sem osso recobrindo esses dentes. O tratamento proposto foi a ulectomia, com a exposição das incisais desses dentes, propiciando a movimentação eruptiva. A paciente ficou em acompanhamento por 6 meses. Conclui-se que frente a possíveis casos de retardo na erupção, a ulectomia se mostra como uma excelente escolha de tratamento, pela sua técnica simples, de recuperação e resultados rápidos, devolvendo para a paciente função e estética. $\mathrm{O}$ cirurgião dentista precisa estar apto para fazer um correto diagnóstico e tratamento nesses casos.

Descritores: Erupção Dentária; Odontopediatria; Cirurgia Bucal.

\section{Abstract}

The process of the tooth eruption chronology is a part from the kids growing and development. However, the delay in teeth eruption is a common thing in many kids, being necessary the dental surgeon and/or pediatric dentist know how to evaluate each situation. One of the reasons related to this delay is the gingival fibrosis, that after a clinical and thorough radiographic examination, as finding the lack of bone tissue, opts for the treatment through the technique of the ulectomy, that consists in exeresis from tissue that revest incisal face from the dental crown from a tooth not erupted, with the purpose of allowing a free way for the tooth to come to your position in the arch. The purpose of this work is to relate a clinical case of no irruption in the teeth 11 and 21. The patient attended to the FAMP's polyclinic with the complaint of a front teeth lack, then after the clinical and radiographic test, was found that this was an eruption delay by a gingival fibrosing and without bone recovering the teeth. The suggested treatment was the ulectomy with the incisal exposition of the teeth, allowing the erruption movement. The patient was accompanied over 6 months. Concludes that the possibility of an eruption delay case. The ulectomy shows up as an excellent choice of treatment, by your simple technique, of recovering and quick results, giving back to the patient the function and the aesthetics. The dentist needs to be willing to do a correct diagnostic and treatment in these cases.

Descriptors: Tooth Eruption; Pediatric Dentistry; Surgery, Oral.

\section{Resumen}

El proceso de cronología de la erupción dental es una parte del crecimiento y desarrollo infantil. Por lo tanto, el retraso en la erupción de los dientes es algo frecuente en muchos niños, haciéndose necesario que el cirujano-dentista o/y odontopediatra sepa avaluar cada caso. Uno de los motivos relacionados a este retraso es la fibrosis gingival, que después de la avaluación clínica y radiográfica minuciosas de la región, presentando la ausencia de tejido óseo, se elige por el tratamiento con la técnica de ulectomía, que consiste en la exéresis de los tejidos que recubren el borde incisal de la corona dental de un diente no erupcionado, a fin de facilitar el camino para que este diente venga a ocupar su posición en la arcada. El objetivo del presente trabajo es relatar un caso clínico de no erupción de los dientes 11 y 21 . La paciente se presentó en la policlínica de la FAMP quejándose de la ausencia de los dientes delanteros, que después del examen clínico y radiográfico se observó que era un caso de retraso de erupción por fibrosis gingival y que no había hueso recubriendo estos dientes. El tratamiento propuesto fue la ulectomía, con la exposición incisal de estos dientes, propiciando el movimiento eruptivo. La paciente estuvo en acompañamiento por 6 meses. Concluyese que delante a posibles casos de retraso en la erupción, la ulectomía es una excelente elección de tratamiento, por su fácil ejecución, de recuperación y resultados rápidos, devolviéndole a la paciente la función dental y estética. El dentista necesita estar apto para hacer un correcto diagnóstico y tratamiento en estos casos.

Descriptores: Erupción Dental; Odontología Pediátrica; Cirugía Bucal.

INTRODUÇÃO

Um dos desafios clínicos que compreende a fase da dentição mista é a impacção de incisivos superiores ${ }^{1}$ sendo uma das maloclusões que mais preocupam os pais e as crianças, devido ao comprometimento estético ${ }^{2,3}$.

A etiopatogenia da impactação dentária é multifatorial, estando relacionados a fatores locais como mau posicionamento do germe dentário, discrepância do arco dentário, condensação óssea exagerada, mucosa resistente e espessa, traumatismo, dentes anquilosados, retenção prolongada ou perda prematura de dentes decíduos, dentes supranumerários e patologias, entre outras razões $^{2,4}$. Outras causas estão relacionadas a fatores gerais como condições hereditárias, desordens endócrinas, palato fissurado, irradiação, disostose cleidocraniana, síndrome de Gardner e síndrome de Down ${ }^{5,6}$.

Dentre estas etiologias, uma que comumente ocasiona a impactação é a presença da gengiva resistente e espessa, conhecida como fibrose gengival, que muitas vezes não é corretamente diagnosticado. Essa fibrose ocorre principalmente sobre os incisivos 
centrais superiores por esfoliações ou perda precoce dos dentes predecessores com atrito superficial dos alimentos durante a mastigação ${ }^{7}$.

A alternativa para quando não ocorre uma erupção dentária espontânea é realizar um procedimento cirúrgico denominado ulectomia, com o objetivo de permitir um caminho livre para esse dente vir a ocupar a sua posição no arco dentário. A técnica consiste na remoção dos tecidos que revestem a face incisal ou oclusal da coroa dentária do dente não irrompido ${ }^{8}$.

A ulectomia está indicada também nos casos em que, sem outro motivo aparente, ocorre retardo da erupção dentária assim como em dentes parcialmente erupcionados e cuja erupção está lenta ${ }^{9}$. No entanto, para uma correta indicação da técnica é preciso associar os exames clínico e radiográfico da região ${ }^{10}$. Através do exame clínico, observa-se uma área com aumento de volume e coloração mais pálida, além de marcas contornadas, denotando a presença do dente não irrompido. Radiograficamente, observa-se a rizogênese do dente atingindo no máximo $2 / 3$ do seu estágio ${ }^{8,10}$.

A técnica cirúrgica da ulectomia envolve incisões elípticas, circulares ou ovais que limitam as áreas para exérese tecidual. Sua extensão deve permitir a exposição do bordo incisal ou face oclusal do dente. A incisão pode ser realizada com bisturi e lâmina, laser ou eletrocautério $^{11}$

Dessa forma esse trabalho tem como objetivo mostrar a importância do diagnóstico correto frente ao retardo da erupção dentária, através das principais características clínicas e radiográficas, por meio de um relato de caso de uma retenção dentária por fibrosamento gengival, onde foi realizada uma ulectomia, com resultados satisfatórios.

\section{CASO CLÍNICO}

Paciente S.M.B., 8 anos, compareceu a policlínica da Faculdade Morgana Potrich FAMP acompanhada pela mãe, com a queixa de que os dentes da frente da filha não nasciam. Segundo a mãe, os dentes da criança haviam esfoliados de modo natural há muito tempo e devido a isso sua filha se sentia diferente dos demais colegas da escola, pois a maioria já tinha os dentes. Na anamnese não apresentou nenhum relato de doenças, uso de medicamentos ou hábitos deletérios. No exame clínico observou-se a presença dos incisivos inferiores e primeiros molares permanentes e ausência de elementos dentários na região dos incisivos centrais superiores, no entanto notouse a presença de uma mucosa gengival fibrosada, de cor rosa pálido. Ao toque observou-se um aumento volumétrico e o contorno do dente permanente que se encontrava recoberto pela gengiva. Deliberou-se o exame radiográfico do tipo periapical, onde constatou-se a presença dos germes dentário 11 e 21, além da inexistência de tecido ósseo da região (Figura 1). Dessa forma, optou-se pelo procedimento cirúrgico, denominado de ulectomia, com intuito de remover o tecido gengival que recobre o dente, a fim de promover sua erupção.

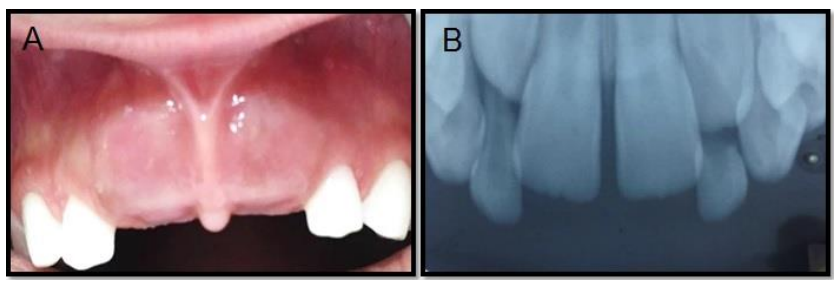

Figura 1: A - Aspecto Clínico Inicial; B - Imagem Radiográfica Inicial.

Após a assepsia e antissepsia, foi realização a anestesia tópica (Lidopass ${ }^{\circledR}$ ) da mucosa seguida na técnica infiltrativa (Alphacaine ${ }^{\circledR}$ ) do nervo alveolar superior anterior e do nervo nasopalatino. Foi feito uma incisão elíptica com o auxílio de um bisturi e lâmina $15 \mathrm{C}$, na vestibular e na palatina, removendo o tecido fibroso que recobria a incisal dos dentes, expondo-as (Figura 2). O sangramento foi cessado com uma compressão rápida com gaze e soro fisiológico. Logo após a cirurgia já observava as incisais dos dentes expostas, e após 7 dias, um terço do dente já estava erupcionado na cavidade bucal. Com 3 meses o dente já se encontrava quase totalmente na boca e com 12 meses em posição funcional (Figura 3), devolvendo a paciente satisfação em sorrir e ausência de problemas emocionais na escola.

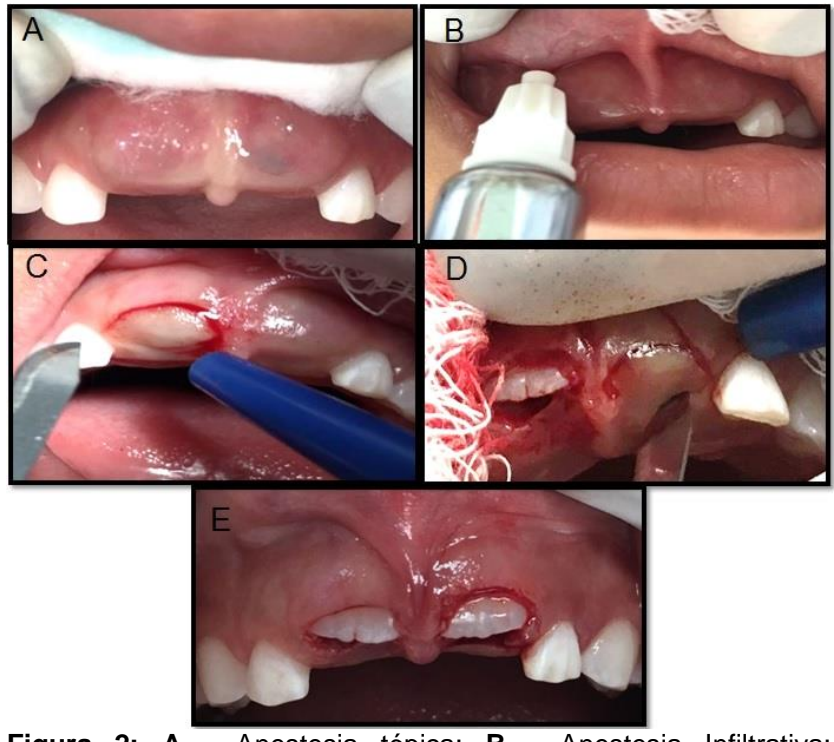

Figura 2: A - Anestesia tópica; B - Anestesia Infiltrativa; C e D - Incisão Elíptica; E - Aspecto Final. 


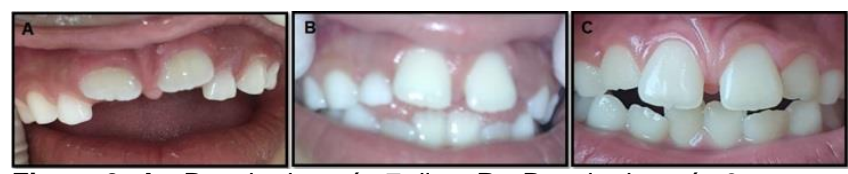

Figura 3: A - Resultado após 7 dias; B - Resultado após 3 meses; C - Resultado após 12 meses.

DISCUSSÃO

O diagnóstico e tratamento de uma retenção de um dente por fibrosamento gengival quando feita no período oportuno torna-se um procedimento simples e de excelente resultado. Neste caso clínico, o exame clínico associado ao radiográfico permitiu ver que os dentes estavam no estágio 8 de Nolla. Segundo Martinez e colaboradores $^{12}$, a verificação radiográfica de impactação de um dente no estágio 8 de Nolla (2/3 da raiz formada) tem a indicação do tratamento por meio de uma ulectomia, pois desde a formação de $1 / 3$ da raiz o dente já apresenta força eruptiva ${ }^{9}$.

À ausência de tecido ósseo, permite a indicação da ulectomia, a fim de permitir a erupção dos dentes, num curto tempo e com fácil execução. No entanto apontam ainda a possibilidade de utilizar-se da ulotomia, mas ressaltam que a possibilidade de reparação tecidual faz com que a técnica seja usada com menos frequência e que a indicação precisa para a técnica se encontra naqueles casos de hematomas de erupção, onde a finalidade é drenar o conteúdo ${ }^{13}$.

A ulectomia permite pequenas variações na sua técnica, podendo ser realizadas incisões elípticas, circulares ou ovais que limitam as áreas para exérese tecidual, além disso pode ser realizada com bisturi e lâmina, laser ou eletrocautério $^{11}$. O uso do bisturi e lâmina neste caso, deu-se pela simplicidade e baixo custo do material, associado ao uso de um anestésico com vasoconstritor contribuindo para a diminuição do fluxo sanguíneo do local.

A retenção dos dentes superiores e anteriores num paciente com idade préescolar gera preocupações aos pais e timidez a criança pelo comprometimento estético e travamento do desenvolvimento psicossocial. Gatto (2015) mostrou no seu estudo que o envolvimento estético desagradável do dente pode rotular uma pessoa e prejudicar a autoestima ${ }^{14}$.

As alterações bucais podem estar presentes de diferentes formas e desde os primeiros anos de vida, tornando-se indispensável o acompanhamento da criança pelo cirurgião-dentista, objetivando o diagnóstico correto e tratamento no momento oportuno, como no caso de impactações por fibrosamento gengival, onde a ulectomia se apresenta como excelente opção de tratamento.
CONCLUSÃO

Conclui-se que, o diagnóstico preciso de impactação por fibrosamento gengival propiciará - tratamento através da técnica cirúrgica "ulectomia", de recuperação rápida e baixo custo. Tal intervenção devolverá ao paciente a estética-funcional, uma oclusão fisiológica normal, além de devolver ao paciente sua autoestima, garantindo o desenvolvimento saudável do seu psicoemocional perante a sociedade.

\section{REFERENCIAS}

1. Lin YTJ. Treatment of an impacted dilacerated maxillary central incisor. Am J Orthod Dentofacial Orthop.1999;115(4):406-9.

2. Noronha MP, Stuani MBS, Stuani AS, Sant'Anna EF. Tracionamento ortodôntico do incisivo central superior. Relato de caso clínico. J Bras Ortodon Ortop Facial. 2002;7(40):339-43.

3. Suri S, Utreja A, Rattan V. Orthodontic treatment of bilaterally impacted maxillary canines in an adult. Am J Orthod Dentofacial Orthop. 2002;122(4):429-37.

4. Kurol J. Early treatment of tooth-eruption disturbances. Am J Orthod 2002;121(6):588-91.

5. Betts A, Camilleri A. A review of 47 cases of unerupted maxillary incisors. Int $\mathrm{J}$ Paediatric Dent. 1999;9(4):285-92.

6. Oliveira MG, Weismann $R$, Júnior ANS, Cerqueira A, Somacal TP. Métodos diagnósticos em retenções dentárias maxilares:relato de 2 casos. Rev Fac Odonto da UFBA. 1999;18:72-5.

7. Guedes-Pinto AC. Odontopediatria. São Paulo:Santos; 2003.

8. Guedes-Pinto AC. Odontopediatria clínica. Série EAP-APCD. São Paulo: Artes Médicas; 1998.

9. Issao M, Guedes-Pinto AC. Manual de Odontopediatria.9.ed.São Paulo:Pancast; 1994.

10. Guedes-Pinto AC. Odontopediatria. 6. ed. São Paulo: Ed. Santos; 1999.

11. Poricelli E, Ponzoni D. Cirurgia bucal pediátrica. In: Toledo OA. Odontopediatria: fundamentos para a prática clínica. 3.ed. São Paulo: Premier; 2005.

12. Martinez JA, Mota LFG, Miranda, IMAD, Guedes-Pinto AC. Cirurgia em odontopediatria. In: Guedes-Pinto AC. Odontopediatria clínica. São Paulo: Artes Médicas; 1998.

13. Silva FWGP. Ojal quirúrgico (ulectomia) ¿cuando y como realizarlo? Reporte de 3 casos clínicos. Ulectomy: when and how to apply. Three case reports Acta Odontol Venez. 2008;46(3)326-28.

14. Gatto RCJ, Garbin AJI, Corrente JE, Garbin CAS. Nível da autoestima de adolescentes brasileiros vítimas de bullying e sua relação com a necessidade de tratamento ortodôntico. Rev Gaúch Odontol. 2017;65(1):30-6. 


\section{CONFLITO DE INTERESSES}

Os autores declaram não haver conflitos de interesse

\section{AUTOR PARA CORRESPONDÊNCIA}

\section{Carla Oliveira Favretto}

Departamento de Odontopediatria

Faculdade Morgana Potrich - FAMP

Av. Antônio Carlos Paniago, 65, Campus II - Centro

75830-000 Mineiros - GO, Brasil

Telefone: (64) 3661-8863

Email: carla.favretto@gmail.com

Submetido em 10/06/2019

Aceito em 23/10/2020 